\section{Commentary: Paving the way for less-invasive lung transplantation: Time to ditch the stich?}

\author{
Ahmed Alnajar, MD, MSPH, ${ }^{\mathrm{a}}$ \\ Ross M. Reul, Jr, BA, BSA, ${ }^{\text {b }}$ and \\ Sameer Hirji, MD, $\mathrm{MPH}^{\mathrm{c}}$
}

Surgical outcomes following lung transplantation have improved dramatically over the past 3 decades, largely due to gradual advances in lung transplantation techniques, improvements in organ selection and recovery, as well as the emergence of advanced adjunctive mechanical support devices. ${ }^{1}$ The conventional suture anastomosis has been the standard approach to vascular anastomoses since specific guidelines for their successful implementation were described by Carrel in $1902,{ }^{2}$ and over the past century, numerous methods for improving vascular connections have been proposed. Rings, stents, adhesives, welding, and staples are among the novel approaches that have been previously presented, ${ }^{3}$ yet nonabsorbable sutures remain the gold standard for most vascular anastomoses. Shi and colleagues ${ }^{4}$ examined the feasibility of an innovative pulmonary artery (PA) anastomosis method for lung transplantation in an attempt to replace the hand-sewn anastomoses. The authors are to be congratulated for their innovative approach, which entailed the use of an endostapler over 2 arterial flaps.

The authors claim that this approach could potentially reduce the anastomosis time and circumvent the learning curve for technical expertise. Although this makes theoretical sense, we anticipate several limitations, although we are still in the infant stages of innovation. In contrast to bowel anastomoses, where staple delivery systems have

\footnotetext{
From the a Division of Cardiothoracic Surgery, University of Miami Miller School of Medicine, Miami, Fla; ${ }^{\mathrm{b}}$ Baylor College of Medicine, Houston, Tex; and ${ }^{\mathrm{c}}$ Brigham and Women's Hospital, Boston, Mass.

Disclosures: The authors reported no conflicts of interest.

The Journal policy requires editors and reviewers to disclose conflicts of interest and to decline handling or reviewing manuscripts for which they may have a conflict of interest. The editors and reviewers of this article have no conflicts of interest

Received for publication Aug 8, 2021; revisions received Aug 8, 2021; accepted for publication Aug 11, 2021; available ahead of print Aug 17, 2021.

Address for reprints: Ahmed Alnajar, MD, MSPH, Division of Cardiothoracic Surgery, University of Miami, 1295 NW 14th St, South Building, Suite J, Miami, FL 33125 (E-mail: alnajarmd@gmail.com).

JTCVS Techniques 2021;9:188-9

2666-2507

Copyright (c) 2021 The Author(s). Published by Elsevier Inc. on behalf of The American Association for Thoracic Surgery. This is an open access article under the CC BY-NC-ND license (http://creativecommons.org/licenses/by-nc-nd/4.0/).

https://doi.org/10.1016/j.xjtc.2021.08.018
}

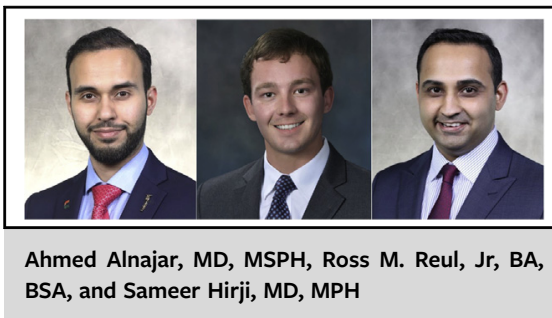

CENTRAL MESSAGE

The concept of minimally invasive lung transplantation is complex. Although using a stapler could have its merits, it is unlikely to reduce transplant complexity or the extended ischemic times.

become ubiquitous, PA anastomoses and most vascular conduits in general, require more precise alignment and tension. The rigidity of a side-to-side arterial flap anastomosis using an endostapler on a thin, compliant vessel raises many concerns related to possible small tears, air leaks, strictures, and dehiscence, especially in immunosuppressed lung transplant patients. Although the proposed methodology offers some merit to support its use in minimally invasive surgeries, the inherent technical challenges preclude its clinical application in its current form. Furthermore, this approach appears to sacrifice vessel length and luminal surface area that may decrease the maximal graft patency, especially because the donor's PA does not come with generous extra length at the time of organ procurement and often necessitates the need for PA plasty. ${ }^{5}$ Thus, although the in vitro results of the proposed method are promising, in that a durable anastomosis could be created in 4.5 minutes without immediate water leaks, the longterm implications of this approach remain to be determined.

The pursuit of a standardized, ideal method for vascular anastomoses is a noble endeavor, especially when it could further facilitate bilateral anterior thoracotomies, yet the proposed approach does not address its proposed benefits, nor improve vessel patency or trauma at the current stage. Novel technologies such as a circular endovascular stapler could solve many of these issues, and the durability of the in vivo staple line at 6 months is promising. However, if we look towards a future where minimally invasive surgeries in lung transplantation is possible, more work needs to be done before we 'ditch the stitch'. 


\section{References}

1. Elgharably H, Javorski MJ, McCurry KR. Bilateral sequential lung transplantation: technical aspects. Available at: https://jtd.amegroups.com/article/view/ 53550. Accessed August 21, 2021.

2. Carrel A. La technique operatoire des anastomoses vasculaires et la transplantation des visceres. Lyon Med. 1902;98:859-64.

3. Zeebregts CJ, Heijmen RH, Van den Dungen JJ, Van Schilfgaarde R. Non-suture methods of vascular anastomosis. Br J Surg. 2003;90:261-71.

4. Shi J, Liu M, He J, Xu X. A new mechanical method for pulmonary artery anastomosis. J Thorac Cardiovasc Surg Tech. 2021;9:185-7.

5. Alnajar A, Chen PC, Burt B, Loor G. Left pulmonary artery patch augmentation for lung transplant in a patient with situs inversus. Tex Heart Inst J. 2021;48:e197112. 